\title{
Hubungan Antara Kecerdasan Emosi dengan Komunikasi Guru di Taman Kanak - Kanak
}

\author{
Yunisa $^{1}$, Ria Novianti ${ }^{2}$, Febrialismanto ${ }^{3}$ \\ Pendidikan Guru Pendidikan Anak Usia Dini, Universitas Riau \\ DOI: 10.31004/aulad.v3i1.57
}

\begin{tabular}{ll}
\hline Article Info & Abstrak \\
\hline Kata kunci: & Tujuan penelitian ini adalah untuk mengetahui tingkat kecerdasan emosional \\
kecerdasan emosional, & guru Taman kanak-Kanak. Menggunakan metode penelitian korelatif. \\
komunikasi, & Variabel penelitian ini adalah kecerdasan emosional dengan komunikasi guru \\
gurupaud. & di TK se-Kecamatan Bangkinang Kota. Jenis penelitian ini adalah korelasi \\
& kuantitatif. Penelitian ini telah dilaksanakan dalam hjangka waktu sekitar 3 \\
& bulan yaitu bulan Desember 2019-Februari 2020. Adapun sampel penelitian \\
& yaitu sebanyak 57 guru di TK se-Kecamatan Bangkinang Kota. Teknik \\
& pengumpulan data yang digunakan yaitu kuesioner (angket). Teknik analisa \\
& data menggunakan teknik korelasi Pearson Product Moment. Dari hasil \\
penelitian diketahui tingkat kecerdasan emosional guru berada dalam \\
kategori sedang dan tingkat komunikasi guru berada dalam kategori sedang. \\
Diketahui bahwa tingkat hubungannya termasuk dalam kategori sedang \\
dengan nilai koefisien determinan adalah sebesar 27,3\% maka dapat \\
diketahui bahwa kecerdasan emosional memberi kontribusi terhadap \\
komunikasi
\end{tabular}

Keywords: emotional intelligence, communication, early childhood teacher.

\begin{abstract}
The purpose of this study was to determine the level of emotional intelligence of kindergarten teachers. Using correlative research methods. The variable of this study is emotional intelligence with teacher communication in kindergartens in Bangkinang City District. This type of research is quantitative correlation. This research has been carried out within a period of about 3 months, from December 2019 to February 2020. The research sample consisted of 57 teachers in kindergartens in Bangkinang City District. Data collection techniques used were questionnaires (questionnaire). Data analysis techniques using Pearson Product Moment correlation techniques. From the results of the study note the level of emotional intelligence of teachers is in the medium category and the level of teacher communication is in the medium category. It is known that the level of relationship is included in the moderate category with a determinant coefficient value of $27.3 \%$, it can be seen that emotional intelligence contributes to communication.
\end{abstract}

\footnotetext{
${ }^{1}$ Pendidikan Guru Pendidikan Anak Usia Dini, Universitas Riau, Riau, Indonesia, Email : yunisa647@gmail.com

${ }^{2}$ S.Psi, M.Pd, Prodi PG-PAUD Universitas Riau, Riau, Indonesia, Email: rianovianti.rasyad@gmail.com

${ }^{3}$ M.Pd, Prodi PG-PAUD Universitas Riau, Riau, Indonesia, Email : febrialisman@gmail.com
} 


\section{PENDAHULUAN}

Pendidikan di sekolah tidak bisa lepas dari proses kegiatan pembelajaran yang meliputi aktivitas yang menyangkut pelaksanaan kegiatan belajar mengajar dan pemberian materi pelajaran agar siswa memperoleh kecakapan pengetahuan yang bermanfaat bagi kehidupan. Proses pelaksanaan pemberian materi yang baik akan memudahkan siswa untuk memahami materi yang sedang diajarkan, sehingga tujuan pembelajaran akan mudah dicapai. Guru sebagai tenaga profesional harus memiliki sejumlah kemampuan, seperti: mengaplikasikan berbagai teori belajar di bidang pengajaran; kemampuan memilih dari menerapkan metode pengajaran yang efektif dan efisien, kemampuan melibatkan siswa berpartisipasi aktif dan kemampuan menciptakan suasana belajar yang menunjang tercapainya tujuan pendidikan. Guru profesional harus memiliki sifat kritis dan mampu berfikir analitis sebagai bentuk kepribadian dari keilmuannya (Sarjana \& Khayati, 2017).

Seorang guru TK yang profesional diharapkan mampu memahami dan mampu menguasai kompetensi yang menjadi tuntutan profesi yang dijalaninya, sehingga dengan kompetensi yang baik maka seorang guru terutama guru TK dapat melaksanakan segala tugas dan tanggung jawabnya secara optimal. Dalam proses pembelajaran guru memegang peran yang sangat penting. Artinya guru memegang tugas dan tanggung jawab merencanakan serta melaksanakan pengajaran di sekolah. Guru harus dapat memberikan rangsangan untuk menimbulkan proses berpikir siswa. Sofia \& Syafrudin (2020) menyatakan Keberhasilan pendidikan sangat ditentukan oleh dua faktor. Faktor pertama adalah kompetensi guru sebagai tenaga pendidik, dan faktor kedua adalah metode pembelajaran yang digunakan oleh pendidik.

Anak usia dini memang perlu perhatian ekstra dan kesabaran yang sangat besar. Komunikasi pada umumnya diartikan sebagai hubungan kegiatan-kegiatan yang berkaitan dengan masalah hubungan, atau diartikan pula sebagai saling tukar-menukar pendapat. Komunikasi juga diartikan hubungan kontak antara manusia baik individu maupun kelompok. Garzia, Yufiarti, \& Hartati (2019) percaya bahwa keterampilan komunikasi merupakan salah satu yang dibutuhkan dalam menjalani proses pembelajaran anak usia dini.

Jadi, seorang guru itu seharusnya mampu mengendalikan emosi saat berkomunikasi dengan sesama guru agar tidak terjadinya kesalahpahaman. Berdasarkan pengamatan yang telah dilakukan di TK Se-kecamatan Bangkinang Kota, terdapat beberapa masalah sebagai berikut: 1) ada sebagian guru yang temperamen, 2) sebagian guru sering membawa masalah pribadi ke sekolah, 3) sebagian guru kurang mau berempati dengan kesedihan guru lainnya yang mendapat musibah, 4) adanya guru yang tidak perhatian dengan guru lain maupun siswanya, 5) adanya guru tidak mau menjalin komunikasi menyediakan fasilitas agar terjadi interaksi antara siswa dan siswa, serta antara siswa dan konsep-konsep yang dipelajarinya sehingga proses berpikir terbina. Berbicara mengenai guru tentu tak lepas dari yang namanya kualitas pembelajaran. Karena kualitas pembelajaran pada suatu sekolah dapat dilihat dari segi proses dan segi hasil pembelajaran pada sekolah tersebut. Kecerdasan emosional menurut Goleman (2006) merupakan kemampuan untuk memotivasi diri sendiri dan bertahan menghadapi frustasi, mengendalikan dorongan hati dan tidak melebih-lebihkan kesenangan, dapat mengatur suasana hati dan mampu menjaga agar beban stres tidak dapat melumpuhkan kemampuan berpikir, dapat berempati dan berdoa.

Menurut Yamin (2012) salah satu yang harus dimiliki oleh seorang guru TK adalah komunikasi profesional, terlebih dalam mendidik anak-anak di dengan guru tertentu karena permasalahan pribadi walaupun sedang berada di sekolah, 6) adanya guru yang tidak sadar bahwa perkatannya membuat guru lain tersinggung.

Berdasarkan masalah-masalah tersebut maka penulis tertarik untuk mengetahui hubungan kecerdasan emosional dengan komunikasi guru di TK Se-kecamatan Bangkinang Kota.

Tujuan Penelitian ini adalah : (1) Untuk mengetahui kecerdasan emosional guru di TK se-Kecamatan Bangkinang Kota, (2) Untuk mengetahui komunikasi guru di TK se-Kecamatan Bangkinang Kota, (3) Untuk mengetahui hubungan kecerdasan emosional dengan komunikasi guru di TK se-Kecamatan Bangkinang Kota.

\section{KAJIAN TEORI}

Menurut Daniel (2009) kecerdasan emosional yaitu kemampuan mengenali perasaan diri sendiri dan perasaan orang lain, kemampuan memotivasi diri sendiri, dan kemampuan mengelola emosi dengan baik pada diri sendiri dan dalam hubungan dengan orang lain. Hal utama dalam mencapai kecerdasan emosional adalah kemampuan seseorang mengenali diri sendiri atau kesadaran diri untuk dapat mengetahui emosional yang akan mucul dalam waktu tertentu.

Adapun 5 aspek kecerdasan emosional menurut (Daniel, 2009) seperti mampu mengenali emosi diri, mampu mengelola emosi diri, dapat memotivasi diri sendiri, dapat mengenali emosi orang lain dan dapat membina hubungan dengan orang lain.

Pendapat dari Mayer, Salovey, \& Caruso (2000) mendefinisikan bahwa kecerdasan emosional sebagai suatu kecerdasan sosial yang berkaitan dengan kemampuan individu dalam memantau baik emosi dirinya maupun emosi orang lain, dan juga kemampuannya dalam membedakan emosi dirinya dengan emosi orang lain, dimana kemampuan ini digunakan untuk mengarahkan pola pikir dan perilakunya. 
Menurut Miller (1986) komunikasi dilakukan jika suatu sumber menyampaikan suatu pesan kepada penerima dengan niat untuk mempengaruhi sikap. Selanjutnya menurut Sukandi (2003) komunikasi merupakan pengungkapan pikiran dan perasaan baik secara lisan maupun tulisan, merupakan kebutuhan setiap manusia dalam rangka pengungkapan dirinya untuk mencapai kepuasan pengungkapan pikiran baik dalam rangka mengungkapkan gagasan sendiri atau menilai gagasan orang lain akan memantapkan pemahaman seseorang tentang apa yang sedang dipikirkan. Yulianti, Jaya, \& Eliza (2019) menggunakan komunikasi, tindakan dan gerakgerik, dengan menggunakan alat peraga dalam pembelajaran menggunakan role playing.

\section{METODE PENELITIAN}

Penelitian ini adalah penelitian jenis korelasi kuantitatif yang telah dilaksanakan dalam jangka waktu sekitar 3 bulan yaitu bulan Desember 2019 hingga Februari 2020 yang bertempatkan di TK se-Kecamatan Bangkinang Kota dengan menghitung besarnya hubungan antara variabel bebas terhadap variabel terikat. Variabel yang dihubungkan dalam penelitian ini adalah kecerdasan emosional sebagai variabel $(X)$ dan komunikasi sebagai variabel (Y).Penelitian ini dilaksanakan di TK se-Kecamatan Bangkinang Kota.

Populasi dalam penelitian ini adalah seluruh guru di TK se-Kecamatan Bangkinang Kota yang berjumlahkan 133 guru. Teknik sampel yang digunakan yaitu random sampling dengan jumlah 57 orang guru. Jadi setiap anggota populasi mempunyai peluang yang sama untuk diambil menjadi sampel dengan menggunakan rumus sebagai berikut:

Dimana:

$$
\mathrm{n}=\frac{N}{N x d^{2}+1}
$$

$$
\begin{array}{ll}
\mathrm{n} & =\text { Jumlah sampel } \\
\mathrm{N} & \text { = Jumlah populasi (133 orang guru) } \\
\mathrm{d}^{2} & \text { = Presisi (ditetapkan 10\% dengan tingkat kepercayaan 95\%) }
\end{array}
$$

(Riduan \& Kuncoro, 2011)

$$
\begin{aligned}
& \mathrm{n}=\frac{133}{133 \times 0.10^{2}+1} \\
& \mathrm{n}=\frac{133}{(133 \times 0.01)+1} \\
& \mathrm{n}=\frac{133}{1,33+1} \\
& \mathrm{n}=\frac{133}{2,33} \\
& \mathrm{n}=57,08 \text { dibulatkan menjadi } 57
\end{aligned}
$$

Jadi, yang akan dijadikan sampel pada penelitian ini adalah berjumlah 57 orang guru TK se-Kecamatan Bangkinang Kota. Sedangkan teknik analisis data yang digunakan untuk menguji hipotesis ini adalah analisis korelasi sederhana Pearson Product Moment yang digunakan untuk mengetahui hubungan antara variabel kecerdasan emosional $(\mathrm{X})$ dengan variabel komunikasi $(\mathrm{Y})$.

$$
r x y=\frac{n\left(\sum x \cdot y\right)-\left(\sum x\right)\left(\sum y\right)}{\sqrt{\left\{n \cdot \sum x^{2}-\left(\sum x\right)^{2}\right\} \cdot\left\{n \cdot \sum y^{2}-\left(\sum y\right)^{2}\right\}}}
$$

Sebelum dilakukan analisis, terlebih dahulu dilakukan uji asumsi berupa uji normalitas, uji linieritas, uji homogenitas dan uji hipotesis.

\section{HASIL DAN PEMBAHASAN}

Deskripsi hasil penyajian data ini berdasarkan penelitian yang telah dilaksanakan. Penelitian ini bertujuan mendapatkan data hubungan kecerdasan emosi dengan komunikasi guru TK di Kecamatan Bangkinang Kota. Berdasarkan dari hasil data yang dilakukan bantuan IBM SPSS Statistik Ver. 20 diperoleh nilai-nilai statistic hasil penelitian secara mendasar seperti $X$ maksimum, $X$ minimum, mean, dan standar deviasi yang nantikan akan digunakan untuk pengkategorian subjek penelitian, gambaran tentang data penelitian secara umum dapat dilihat pada tabel deskripsi data penelitian, dimana dari data tersebut dapat diketahui fungsi-fungsi statistik secara mendasar. Dimana penelitian ini bertujuan untuk mendapatkan data tentang bagaimana hubungan kecerdasan emosi dengan komunikasi guru TK di Kecamatan Bangkinang Kota. 
Tabel 1 Deskripsi Hasil Penelitian

\begin{tabular}{lcccccccc}
\hline \multicolumn{1}{c}{ Variabel } & \multicolumn{3}{c}{ Skor X yang dimungkinkan (Hipotetik) } & \multicolumn{5}{c}{ Skor X yang diperoleh (Empirik) } \\
\hline & $\mathbf{X}_{\min }$ & \multicolumn{1}{c}{$\mathbf{X}_{\max }$} & Mean & SD & $\mathbf{X}_{\min }$ & $\mathbf{X}_{\max }$ & Mean & SD \\
\hline Kecerdasan Emosional & 40 & 59 & 48 & 5 & 20 & 80 & 50 & 10 \\
Komunikasi & 35 & 48 & 41 & 3 & 16 & 64 & 40 & 8 \\
\hline
\end{tabular}

Sumber: Olahan Data Penelitian, 2020

\section{Deskripsi Kecerdasan Emosional}

Data kecerdasan emosi terdiri dari 20 item pernyataan dari 5 indikator dapat dilihat pada tabel berikut ini:

Tabel 2 Indikator Kecerdasan Emosi Guru TK di Kecamatan Bangkinang Kota

\begin{tabular}{|c|c|c|c|c|c|c|}
\hline No & Indikator & Jumlah Item & Skor Faktual & Skor Ideal & Persentase & Kategori \\
\hline 1 & Mengenali emosi diri & 3 & 377 & 684 & $55 \%$ & Rendah \\
\hline 2 & Mengelola emosi & 8 & 1044 & 1824 & $57 \%$ & Sedang \\
\hline 3 & Memotivasi diri sendiri & 4 & 517 & 912 & $57 \%$ & Sedang \\
\hline 4 & $\begin{array}{l}\text { Mengenali emosi orang } \\
\text { lain }\end{array}$ & 4 & 514 & 912 & $56 \%$ & Sedang \\
\hline 5 & Membina hubungan & 2 & 273 & 456 & $60 \%$ & Sedang \\
\hline & Jumlah/Rata-rata & 21 & 2725 & 4788 & $56,05 \%$ & Sedang \\
\hline
\end{tabular}

Dari tabel 2 diatas menunjukkan data mengenai kecerdasan emosional guru TK secara keseluruhan yaitu nilai skor 2725 atau sekitar $56,05 \%$ menunjukkan bahwa kecerdasan emosional guru termasuk dalam kategori sedang yaitu $56,05 \%$ dalam rentang $56 \%-66 \%$.

Tabel 3 Distribusi Frekuensi Kecerdasan Emosional Guru TK se-Kecamatan Bangkinang Kota

\begin{tabular}{cccc}
\hline No & Interval & Frekuensi & Persentase \\
\hline 1 & $40-42$ & 12 & $21,05 \%$ \\
2 & $43-45$ & 8 & $14,04 \%$ \\
3 & $46-48$ & 13 & $22,81 \%$ \\
4 & $49-51$ & 8 & $14,04 \%$ \\
5 & $52-54$ & 11 & $19,30 \%$ \\
6 & $55-57$ & 3 & $5,26 \%$ \\
7 & $58-60$ & 2 & $3,51 \%$ \\
\hline
\end{tabular}

Sumber: Olahan Data Penelitian, 2020

Tabel 4 Kategori Variabel Kecerdasan Emosional

\begin{tabular}{llccc}
\hline No & \multicolumn{1}{c}{ Kategori } & Interval & Frekuensi & Persentase \\
\hline 1 & Sangat tinggi & 55,5 & 3 & $5,26 \%$ \\
\hline 2 & Tinggi & $50,5-55,5$ & 16 & $28,10 \%$ \\
\hline 3 & Sedang & $45,5-50,5$ & 18 & $31,60 \%$ \\
\hline 4 & Rendah & $40,5-45,5$ & 17 & $29,82 \%$ \\
\hline 5 & Sangat rendah & 40,5 & 3 & $5,26 \%$ \\
\hline
\end{tabular}

Sumber: Olahan Data Penelitian 2020

\section{Deskripsi Komunikasi}

Data komunikasi terdiri dari 16 item pernyataan dari 5 indikator dapat dilihat pada tabel berikut ini:

Tabel 5 Indikator Komunikasi Guru TK di Kecamatan Bangkinang Kota

\begin{tabular}{clccccc}
\hline No & \multicolumn{1}{c}{ Indikator } & Jumlah Soal & Skor Faktual & Skor Ideal & Persentase $\%$ & Kriteria \\
\hline 1 & Komunikasi Verbal & 8 & 1083 & 1824 & $59 \%$ & Sedang \\
2 & $\begin{array}{l}\text { Komunikasi } \\
\text { Nonverbal }\end{array}$ & 8 & 1212 & 1824 & $66 \%$ & Sedang \\
\hline & Jumlah/ Rata-Rata & $\mathbf{1 6}$ & $\mathbf{2 2 9 5}$ & $\mathbf{3 6 4 8}$ & $\mathbf{6 3 \%}$ & Sedang \\
\hline
\end{tabular}


Dari tabel 5 diatas menunjukkan data mengenai komunikasi guru TK secara keseluruhan yaitu nilai skor 2295 atau sekitar 63\% menunjukkan bahwa kecerdasan emosional guru termasuk dalam kategori sedang.

\section{Hubungan antara Kecerdasan Emosional dengan Komunikasi Guru TK di se-Kecamatan Bangkinang Kota Uji Normalitas}

Tabel 6 Normalitas data Variabel Penelitian

\begin{tabular}{llr|lr}
\hline & & $\begin{array}{c}\text { Kecerdasan } \\
\text { Emosional }\end{array}$ & \multicolumn{1}{c}{ Komunikasi } \\
\hline $\mathrm{N}$ & Mean & 57 & \\
Normal Parameters ${ }^{\mathrm{a}, \mathrm{b}}$ & 47.8070 & Normal Parameters & \\
& Std. Deviation & 4.99799 & \\
& Absolute & .095 & Most Extreme Differences \\
Most Extreme Differences & Positive & .095 & \\
& Negative & -.080 & .850 \\
Kolmogorov-Smirnov Z & & .718 & .466 \\
Asymp. Sig. (2-tailed) & & .681 & \\
\hline
\end{tabular}

Sumber: Data Olahan Penelitian, 2020

Hasil perhitungan normalitas distribusi data diketahui hasil Kolmogorov-Smirnov Test variabel kecerdasan emosi sebesar 0,718 dan variabel komunikasi guru sebesar 0,850, dangan nilai signifikansi variabel kecerdasan emosidankomunikasi guru TK di Kecamatan Bangkinang Kota sebesar 0,681 dan 0,466 yang lebih besar dari 0,05 yang berarti seluruh distribusi item hasil penelitian berdimensi normal.

\section{Uji Homogenitas}

Berdasarkan nilai varian dari kedua kelas di atas, maka dilakukan uji homogenitas. Hasil ini dapat digambarkan dalam tabel di bawah ini:

Tabel 7 Uji Homogenitas data Variabel Penelitian

\begin{tabular}{cccc}
\hline Levene Statistic & $\mathrm{df1}$ & $\mathrm{df2}$ & Sig. \\
\hline 1.464 & 15 & 38 & .169 \\
\hline
\end{tabular}

Dari keterangan tabel 7 dapat dijelaskan bahwa nilai levene tes dengan sig 0,169 yang berarti lebih besar dari 0,05. Hal ini menandakan bahwa seluruh data homogen.

\section{Uji Linearitas}

Selanjutnya untuk melihat tingkat linearitas data digunakan Anova atau $\mathrm{F}$ test. Untuk lebih jelasnya dapat diperhatikan dalam tabel linearitas berikut:

Tabel 8 Uji Linearitas data Variabel Penelitian

\begin{tabular}{|c|c|c|c|c|c|c|c|}
\hline \multicolumn{8}{|c|}{ ANOVA Table } \\
\hline & & & $\begin{array}{l}\text { Sum of } \\
\text { Squares }\end{array}$ & $d f$ & Mean Square & $F$ & Sig. \\
\hline \multirow{6}{*}{$\begin{array}{l}\text { Komunikasi * } \\
\text { Kecerdasan }\end{array}$} & \multirow{4}{*}{$\begin{array}{l}\text { Between } \\
\text { Groups }\end{array}$} & (Combined) & 1297.083 & 20 & 64.854 & 3.268 & .001 \\
\hline & & Linearity & 1037.309 & 1 & 1037.309 & 52.270 & .000 \\
\hline & & Deviation & 259.773 & 19 & 13.672 & .689 & .805 \\
\hline & & $\begin{array}{l}\text { from } \\
\text { Linearity }\end{array}$ & & & & & \\
\hline & \multicolumn{2}{|c|}{ Within Groups } & 714.426 & 36 & 19.845 & & \\
\hline & \multicolumn{2}{|l|}{ Total } & 2011.509 & 56 & & & \\
\hline
\end{tabular}

Sumber: Data Olahan Penelitian, 2020

Dari data di atas diketahui bahwa data berpola linear yang ditunjukkan oleh nilai sig Linierity 0,000. Berdasarkan uji normalitas, homogenitas dan linearitas variabel kecerdasan emosi dan komunikasi guru TK di se-Kecamatan Bangkinang Kota memenuhi persyaratan untuk menggunakan rumus product moment. 


\section{Uji Hipotesis}

Pengujian hipotesis penelitian dilakukan untuk membuktikan adanya hubungan kecerdasan emosi dan komunikasi guru TK di se-Kecamatan Bangkinang Kota. Adapun cara yang dilakukan adalah dengan menggunakan analasis korelasi product moment. Adapun nilai yang didapatkan adalah nilai $r$ untuk mengetahui besarnya korelasi. Kemudian dilakukan pencarian besar persentase hubungan yang didapatkan. Dengan demikian uji korelasi ini berfungsi untuk menguji hipotesis yang ditetapkan sebelumnya. Adapun hipotesis yang akan diuji adalah sebagai berikut :

Adapun hipotesis yang akan diuji dalam penelitian ini adalah :

$\mathrm{H}_{\mathrm{o}}=$ Tidak terdapat hubungan kecerdasan emosi dan komunikasi guru TK di Kecamatan Bangkinang Kota.

$\mathrm{H}_{\mathrm{a}}=$ Terdapat hubungan kecerdasan emosi dan komunikasi guru TK di Kecamatan Bangkinang Kota. Untuk menghitung nilai korelasi tersebut, maka agar lebih jelas dapat diperhatikan pada tabel berikut:

Tabel 9 Hubungan Kecerdasan Emosi dengan Komunikasi Guru TK di Kecamatan Bangkinang Kota

\begin{tabular}{llrr}
\hline & & Kecerdasan Emosional & Komunikasi \\
\hline \multirow{2}{*}{ Kecerdasan } & Pearson & 1 & $.523^{* *}$ \\
Emosional & Correlation & & .000 \\
& Sig. (2-tailed) & 57 & 57 \\
& $\mathrm{~N}$ & $.523^{* *}$ & 1 \\
& Pearson & & \\
& Komunikasi & .000 & 57 \\
& Sig. (2-tailed) & 57 & \\
& $\mathrm{~N}$ & 57
\end{tabular}

Sumber: Data Olahan Penelitian, 2020

Sebagai kriteria penilaian, apabila probabilitas > 0,05 maka Ho diterima, sedangkan apabila probabilitas < 0,05 maka Ho ditolak (Sugiyono, 2013). Pada hasil uji korelasi diperoleh angka probabilitas sebesar 0,000 dimana 0,000 lebih kecil dari 0,05 $(0,000<0,05)$ maka Ho ditolak artinya terdapat hubungan atau korelasi yang signifikan antara kecerdasan emosional dengan komunikasi guru. Koefisien korelasi yang dihasilkan adalah 0,523 yang terletak pada rentang 0,40-0,599 kategori sedang.

\section{Koefisien Determinasi}

Tabel 10 Besarnya Hubungan Kecerdasan Emosional dengan Komunikasi Guru TK di se-Kecamatan Bangkinang Kota

\begin{tabular}{lrrrr}
\hline Model & R & R Square & Adjusted R Square & Std. Error of the Estimate \\
\hline 1 & $.523^{\mathrm{a}}$ & .273 & .260 & 2.28653 \\
\hline
\end{tabular}

Sumber: Data Olahan Penelitian, 2020 (Lampiran 18)

Berdasarkan tabel 10 diatas koefisien determinasi yang dihasilkan adalah sebesar $r^{2}=0,273$. Artinya $27,3 \%$ variabel kecerdasan emosional menentukan komunikasi. Sedangkan arah hubungan adalah positif karena nilai $r$ positif, berarti semakin tinggi kecerdasan emosional guru maka semakin tinggi komunikasi guru.

\section{Pembahasan}

Berdasarkan hasil penelitian, menunjukkan jumlah skor masing-masing aspek dari kecerdasan emosional guru TK, dimana secara deskriptif dapat ditunjukkan bahwa nilai (skor) terendah adalah dari aspek mengenali emosi diri dengan skor sebesar 377 atau 55\%, dan yang paling tinggi adalah aspek kelima yakni membina hubungan dengan skor aspek sebesar 273 atau 60\% dari yang diharapkan.

kecerdasan emosional memiliki hubungan yang tinggi dengan efikasi guru, yang artinya juga memiliki pengaruh terhadap kinerja dari guru yang bersangkutan apabila memiliki kecerdasan emosional yang tinggi pula (Arinda \& Setyawan, 2013).

Kecerdasan emosional menunjuk kepada suatu kemampuan untuk memahami perasaan diri masingmasing dan perasaan orang lain, kemampuan untuk memotivasi dirinya sendiri dan menata dengan baik emosiemosi yang muncul dalam dirinya dan dalam berhubungan dengan orang lain atau lingkungannya (Gitosaroso, 2012). Selain itu dalam penelitian dijelaskan bahwa kecerdasan emosional mempunyai pengaruh positif tehadap kesuksesan dan kinerja pada individu (Wibowo, 2017). Sedangkan untuk variabel komunikasi guru, angket 
penelitian yang digunakan mengacu pada aspek penelitian yang meliputi yaitu: 1) komunikasi verbal, dan 2) komunikasi nonverbal.

Berdasarkan hasil penelitian, jumlah skor masing-masing indikator dari komunikasi guru TK, dimana secara deskriptif dapat ditunjukkan bahwa nilai (skor) terendah yakni komunikasi verbal dengan skor indikator sebesar 1083 atau 59\%, skor tertinggi yakni komunikasi nonverbal dengan skor indikator sebesar 1212 atau 66\%. Komunikasi guru TK Se-Kecamatan Bangkinang Kota tergolong sedang dengan persentase keseluruhan 63\%. Data mengenai komunikasi guru secara keseluruhannya dengan nilai $63 \%$ termasuk dalam kategori sedang yaitu dalam rentang $56 \%-66 \%$

Relevan dengan penelitian yang menjelaskan bahwa bahwa faktor ekspresi wajah menjadi faktor yang paling berpengaruh terhadap komunikasi efektif. Selain itu keterampilan komunikasi guru menjadi syarat dalam memudahkan siswa dapat menerima dengan mudah bahan pembelajaran untuk mencapai perubahan kognitif, afektif dan psikomotorik (Taufik, 2018). Komunikasi dalam pembalajaran dewasa ini mendapatkan perhatian yang luar biasa. Hal ini dilatarbelakangi pentingnya memilih cara komunikasi dalam proses pembelajaran agar kegiatan tersebut mencapai tujuan secara efektif dan efesien. Komunikasi yang efektif berkolerasi dengan tingkat keberhasilan pembelajaran (Masdul, 2018).

Berdasarkan perhitungan maka disimpulkan bahwa Terdapat hubungan kecerdasan emosi dan komunikasi guru TK di Se-Kecamatan Bangkinang Kota. Besar hubungan kecerdasan emosional dan komunikasi guru TK di SeKecamatan Bangkinang Kota sebesar 27,3\%\%, sedangkan nilai korelasi diperoleh secara positif sebesar 0,523 dengan probabilitas sebesar 0,000 . Hal ini menjelaskan bahwa Ha dapat diterima dan Ho ditolak. Sehingga dapat disimpulkan bahwa korelasi antara variabel $\mathrm{X}$ (kecerdasan emosional) dan variabel $\mathrm{Y}$ (komunikasi guru) terdapat hubungan positif diantara kedua variabel tersebut. Artinya semakin tinggi kecerdasan emosional guru dalam mengajar, maka akan semakin tinggi pula kemampuan komunikasi guru atau sebaliknya. Artinya, dengan kemampuan komunikasi yang dimiliki guru, maka akan memudahkan anak menerima pembelajaran, sehingga terjadi perubahan dari segi kognitif, afektiif dan psikomotorik anak. Selain itu, komunikasi yang baik yang dimiliki guru juga akan mendukung tercapaikan tujuan pembelajaran yang diharapkan.

Berdasarkan penelitian terdahulu yang meneliti hubungan kecerdasan emosional guru dengan kompetensi guru khususnya komunikasi. Terdapat hubungan yang cukup kuat dan signifikan antara kecerdasan emosional dengan kompetensi (Astuti, 2013). Sedangkan penelitian Darojah \& Hadijah (2016) mengatakan bahwa terdapat hubungan yang cukup kuat dan signifikan antara kompetensi kepribadian dengan komunikasi guru.

Dengan demikian dapat disimpulkan bahwa hubungan kecerdasan emosional dengan komunikasi guru TK di Se-Kecamatan Bangkinang Kota tergolong sedang. Hal ini ditunjukkan bahwa persentase terbesar 0, 523 dimiliki guru TK di se-Kecamatan Bangkinang Kota dengan kriteria sedang.

\section{SIMPULAN}

Terdapat hubungan positif antara kecerdasan emosional dengan komunikasi guru di TK Se-kecamatan Bangkinang Kota. Sesuai dengan kesimpulan hasil penelitian, maka dapat dikemukakan beberapa rekomendasi, yaitu : bagi guru-guru dapat meningkatkan kecerdasan emosional dan komunikasi guru sebagai pendidik anak usia dini yang dipersiapkan untuk mendidik kejenjang yang lebih lanjut. Untuk itu diharapkan guru yang lebih optimal dalam menjalankan tugas sebagai pendidik supaya tercapainya tujuan yang diharapkan bersama, baik bagi guru sendiri maupun sekolah, bagi kepala sekolah dapat meningkatkan komunikasi dengan memberikan motivasi dan menjalin kerjasama yang baik misalnya saling menghargai dan memberikan kritikan yang membangun sehingga hubungan lebih harmonis dan guru-guru diperhatikan untuk selalu menjalin hubungan kecerdasan emosional yang baik, dan bagi peneliti selanjutnya hasil penelitian ini belum sempurna dan masih banyak kekurangan. Selain itu hendaknya melengkapi penelitian ini dengan menambah variabel yang lainnya yaitu kecerdasan interpersonal, komunikasi interpersonal, dan variabel yang lain yang bermanfaat bagi peneliti peneliti selanjutnya.

\section{DAFTAR PUSTAKA}

Arinda, A. S., \& Setyawan, I. (2013). Hubungan Antara Kecerdasan Emosional dengan Efikasi Diri Guru Rintisan Sekolah Bertaraf Internasional (RSBI) di SMA Negeri 1 Purwodadi. Empati: Jurnal Karya IImiah S1 Undip, 2(3), 231-239.

Astuti, S. Y. (2013). Hubungan Antara Kecerdasan Emosional dengan Kompetensi Guru di TK Kecamatan Laweyan. Universitas Muhammadiyah Surakarta.

Daniel, G. (2006). Kecerdasan Emosional. Jakarta: PT. Gramedia Pustaka Utama.

Daniel, G. (2009). Kecerdasan Emosional: mengapa El lebih penting dari IQ. Jakarta: PT. Gramedia Pustaka Utama.

Darojah, N. R., \& Hadijah, H. S. (2016). Analisis Pengaruh Kompetensi Kepribadian Guru Dengan Motivasi Belajar Sebagai Variabel Intervening Terhadap Prestasi Belajar Siswa Kelas X 
Administrasi Perkantoran. Jurnal Pendidikan Manajemen Perkantoran, 1(1), 109. https://doi.org/10.17509/jpm.v1i1.3344

Garzia, M., Yufiarti, Y., \& Hartati, S. (2019). Perbedaan Kesiapan Sekolah Anak Usia Dini di Daerah Pesisir Ditinjau dari Status Ekonomi Orang Tua dan Parenting. Jurnal Obsesi : Jurnal Pendidikan Anak Usia Dini, 3(2), 470. https://doi.org/10.31004/obsesi.v3i2.239

Gitosaroso, M. (2012). Kecerdasan Emosi ( Emotional Intelligence ) dalam Tasawuf. Jurnal Khatulistiwa, 2(2), 182-200.

Masdul, M. R. (2018). Komunikasi Pembelajaran. IQRA: Jurnal IImu Kependidikan Dan Keislaman, 2(1), 13-28. Retrieved from https://mangmumin.blogspot.com/2016/10/makalah-komunikasipembelajaran.html

Mayer, J. D., Salovey, P., \& Caruso, D. R. (2000). Models of emotional intelligence. RJ Sternberg.

Miller, D. (1986). Configurations of strategy and structure: Towards a synthesis. Strategic Management Journal, 73), 233-249. https://doi.org/10.1002/smj.4250070305

Riduan, \& Kuncoro, E. A. (2011). Cara Menggunakan dan Memaknai Analisis Jalur (Path Analysis) (Cetakan Ke). Bandung: Alfabeta.

Sarjana, S., \& Khayati, N. (2017). Pengaruh Etika, Perilaku, Dan Kepribadian Terhadap Integritas Guru. Jurnal Pendidikan Dan Kebudayaan, 1(3), 379. https://doi.org/10.24832/jpnk.v1i3.450

Sofia, A., \& Syafrudin, U. (2020). Pemahaman Guru TK tentang Metode Sosiodrama terhadap Kompetensi Sosial. Aulad: Journal on Early Childhood, 2(3), 105-112. https://doi.org/10.31004/aulad.v2i3.39

Sukandi, U. (2003). Belajar Aktif dan Terpadu (Apa, Mengapa dan Bagaimana). Surabaya: Graha Pustaka.

Taufik, A. (2018). Keterampilan Komunikasi Guru Profesional di Sekolah. IJTIMAIYAH Jurnal IImu Sosial Dan Budaya, 2(1).

Wibowo, C. T. (2017). Analisis Pengaruh Kecerdasan Emosional (EQ) dan Kecerdasan Spiritual (SQ) pada Kinerja Karyawan. Jurnal Bisnis Dan Manajemen, 15(1), 1. https://doi.org/10.20961/jbm.v15i1.4108

Yamin, M. (2012). Panduan Pendidikan Anak Usia Dini. Jakarta: Gaung Persada.

Yulianti, E., Jaya, I., \& Eliza, D. (2019). Pengaruh Role Playing terhadap Pengenalan Literasi Numerasi di Taman Kanak-kanak Twin Course Pasaman Barat. Aulad : Journal on Early Childhood, 2(2), 4150. https://doi.org/10.31004/aulad.v2i2.33 